\title{
Improvement of Four Wheel Steering System
}

\section{Seda POSTALCIOĞLU ${ }^{1 *}$}

\begin{abstract}
The aim of this study is improving the vehicle safety and driver comfort. Four Wheel Steering (4WS) is used with Lane Keeping System (LKS) for confirmation the efficiency of the integrated controller. A two-degree-of-freedom model is used for simulation. Simulation is described for different driver models, different speeds on the vehicle with controllers. As seen from the simulation results, 4WS helps to the vehicle not to swerve but increase lateral displacement and driver workload. LKS is used to solve this problem. 4WS is supported by LKS. System is evaluated using performance indexes. Simulation results show that using the driver assistance systems together, improves vehicle safety and driver comfort.
\end{abstract}

Keywords: 4WS, vehicle safety, driver comfort

${ }^{1}$ Seda POSTALCIOĞLU (Orcid ID: 0000-0002-3188-8116), Bolu Abant Izzet Baysal University, Faculty of Engineering, Department of Computer Engineering Gölköy Campus, Bolu, Turkey.

*Sorumlu Yazar / Corresponding Author: Seda POSTALCIOĞLU, e-mail: postalcioglu_s@ibu.edu.tr 


\section{INTRODUCTION}

The safety of driving cars could be significantly increased by using driver assistance systems (Risack et al., 2000). There are some studies in the last year about 4WS. Bak and Jakobsen are studied about agricultural robotic platform with 4WS for weed detection (Bak and Jacobsen,2004). Stochastic stability of 4WS is studied in the paper of Huang et al. (Huang et al., 2007). Four-wheel steering and direct yawmoment integrated fuzzy controller is designed by Zhang and Liu to verify the effectiveness of the integrated fuzzy controller for computer simulation (Zhang and Liu, 2011). 4WS vehicles have been studied in order to improve the maneuverability of vehicle at low speed and enhance the stability at high speed ( $\mathrm{Yu}$ et al.,2016).

To improve the lateral stability is not the only aim of this study. One of the other important thing is the driver workload. The driver could be awareness or sleepless, on this condition to make an accident is inevitable. The LKS can warn the driver for the dangerous unintentional departure from the lane and then control the vehicle steering mechanism. LKS helps the driver to keep the car within the lane. Using steering control systems helps to improve the lateral stability (Mostavi et al.,2004). A driving simulator was used to determine changes in mental effort in response to manipulations of steering demand are studied by Dijksterhuis et al. (Dijkserhuis et al., 2011). A nested PID steering control in vision based autonomous vehicles is designed by Marino et al. and experimentally tested to perform path following (Marino et al., 2011). The aim of this study is to use $4 \mathrm{WS}$ and LKS together to improve the vehicle safety and driver comfort. The main contributions of this paper are:

- Effects of 4WS are examined for different driver model and different vehicle speeds,

- 4WS is supported by LKS to improve the vehicle safety and driver comfort

- Performances are evaluated and shown in graphics.

\section{MATERIAL AND METHODS}

\section{System Structure}

It is necessary to reduce degree of freedom (DOF) of vehicle dynamic model in order to control in real time (Yang et al., 1999). Thus, the simplified model is applied to vehicle dynamic model in this study. The simplified model is shown in Figure 1 (Zhang et al., 2007).

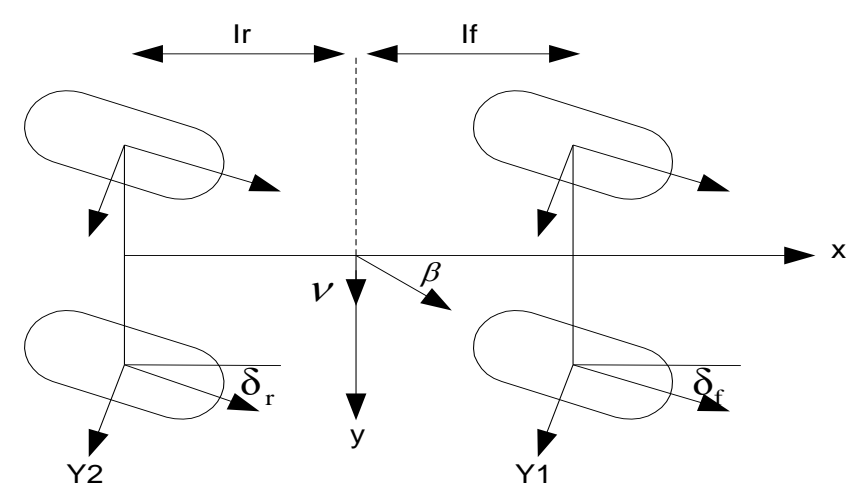

Figure 1. Vehicle dynamic model

The vehicle's state space model for the simulation is shown in Equation 1 (Pruckner and Fischer, 2000). $\delta_{\mathrm{f}}$ and $\delta_{\mathrm{r}}$ represent front and rear wheel steering angle, respectively. Y1 and Y2 represent the lateral force of front and rear wheel. $\mathrm{v}$ is vehicle forward velocity. If is the distance from the height of center of gravity (CG) to front axle, $I_{r}$ is the distance from $C G$ to rear axle. $\beta$ is the body sideslip angle. $C_{f}$ is the front wheel cornering stiffness, $\mathrm{C}_{\mathrm{r}}$ is the rear wheel cornering stiffness. 


$$
\left[\begin{array}{c}
\dot{\beta} \\
\ddot{\psi}
\end{array}\right]=\left[\begin{array}{cc}
-\frac{C_{f}+C_{r}}{m V} & -1+\frac{I_{f} C_{f}-I_{r} C_{r}}{m V^{2}} \\
\frac{I_{r} C_{r}-I_{f} C_{f}}{i_{z}} & \frac{-I_{f}^{2} C_{f}-I_{r}^{2} C_{r}}{i_{z} V}
\end{array}\right]\left[\begin{array}{l}
\beta \\
\dot{\psi}
\end{array}\right]+\left[\begin{array}{cc}
\frac{C_{f}}{m V} & \frac{C_{r}}{m V} \\
\frac{I_{f} C_{f}}{i_{z}} & -\frac{I_{r} C_{r}}{i_{z}}
\end{array}\right]\left[\begin{array}{l}
\delta_{f} \\
\delta_{r}
\end{array}\right]
$$

It is difficult to find an universal driver model due to the variations in the psychological aspect of human being. Driver's behavior can be modeled

$$
G(s)=h \frac{e^{-t_{d} s}}{1+t_{m} s}
$$

Where $\mathrm{h}$ is the proportional gain, $t_{d}$ represents the driver's reaction time, and $t_{m}$ is the neuromotor time constant. Two types of driver are taken into the consideration: young and old drivers. The number of older drivers in the industrialized world is rising steadily. This leads to increasing concern about traffic safety as ageing is commonly associated with psycho physiological changes which can decrease driving ability (Fofanova and Vollrath, 2011). This statement points the importance of the driver assist systems. DM-1 and DM-2 are young and old driver models, respectively. Different driver models are used for the lane keeping system by Özgen (Özgen 2010).

\section{Design of Four Wheel Steering System}

The large proportion of accidents related to lateral control indicates the relevance of research into factors associated with inadequate steering behavior (Dijksterhuis et al., 2011). 4WS controllers are such that in high speed, steering angle of rear and front wheels are in the same direction to improve stability of vehicle and satisfy passenger relaxation (Zhang et al., 2007). But in low speed, the steering angle of front and as seen in Equation 2 (Feng,2000; Leelavansuk et al., 2003; Özgen, 2012).

rear wheels are chosen in the opposite direction to improve maneuverability of vehicle (Zhang et al., 2007). The safety is important for the vehicle design.

The objective of the control system is to regulate the lateral deviation at the center of gravity and yaw deviation of the vehicle to be zero. In order to improve handling and stability of the vehicle, the side slip angle and the yaw rate of the vehicle are controlled to trace their desired values. The structure of the controller which makes the vehicle follow the reference model response as shown in Figure 2. The model matching controller which is used in this study including the reference model enables the output variables to follow the reference model. The basic concept of the model matching control is shown in Fig. 2 (Kwon et al., 2005).

In this paper the reference model is assumed as the following response model. The following response model is derived by $4 \mathrm{WS}$ in which the rear wheel is actively steered on the basis of zero side slip in the vehicle body. The reference model can be described as shown in Equations (3),(4),(5): (Nagai et al., 2002). 


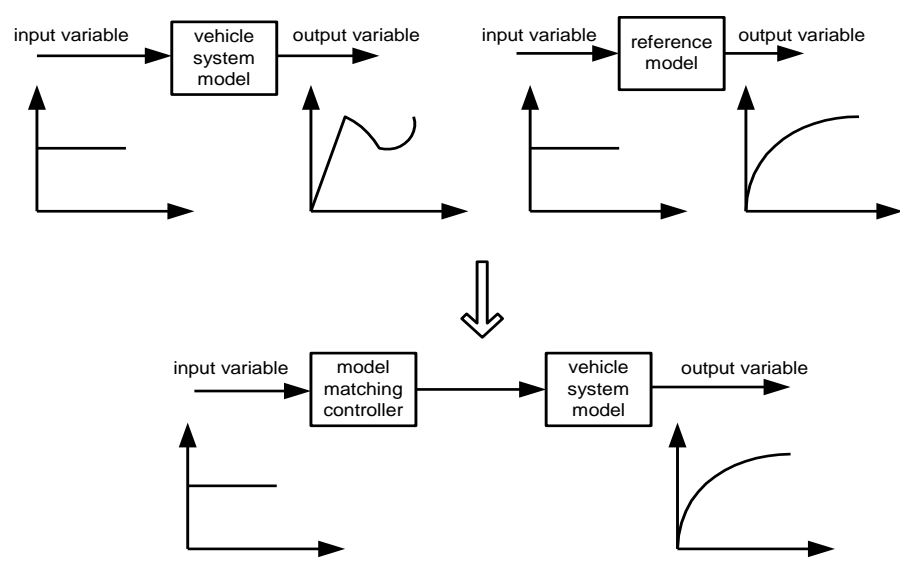

Figure 2. The structure of the model matching controller

$$
\begin{aligned}
& X_{d}=\left[\begin{array}{l}
\beta_{d} \\
\dot{\psi}_{d}
\end{array}\right]=\left[\begin{array}{c}
0 \\
\frac{k_{\dot{\psi} d}}{1+\tau_{\dot{\psi} d} s}
\end{array}\right] \delta_{f} \\
& k_{\dot{\psi} d}=\frac{V}{L_{f}+m L_{f} L_{r} V^{2} / 2 C_{f} L_{f}\left(L_{f}+L_{r}\right)} \\
& \tau_{\dot{\psi} d}=\frac{I_{z} V}{2 C_{f} L_{f}\left(L_{f}+L_{r}\right)+m L_{r} V^{2}}
\end{aligned}
$$

$\dot{\Psi}$ is the yaw rate, $\mathrm{m}$ is the vehicle mass. The performances of the controllers are evaluated using four performance indexes as Lane Keeping Performance (LKP), Yaw Rate Performance (YRP), Sideslip Angle Performance (SAP), Driver Workload Performance (DWP). The performance equations are given in the papers (Leelavansuk et al.,2003;Özgen 2010;Özgen 2010).

\section{RESULTS AND DISCUSSION}

In this section different conditions are taken into consideration. The aim is to improve the comfort of the vehicle and to reduce the driver workload. 4WS improves the yaw rate and sideslip angle performances but lateral displacement and driver workload performances are not fine enough in the simulations. To make lateral displacement and driver workload performances better $4 \mathrm{WS}$ control structure is supported by LKS. Figure 3 shows the structure of the designed system.

Lane Keeping System (LKS) helps the driver to keep the lane by producing impulses through the steering wheel. LKS helps reducing required driver workload from the driver and improving lane keeping efficiency. LKS calculates an optimal steering wheel angle. Below simulation case studies are done using drivervehicle closed loop. Classic vehicle which doesn't have any control algorithms is compared with 4WS and improved of 4WS.

Case 1: Figure 4 represents the results of $4 \mathrm{WS}$ for DM-1. Vehicle speed is $50 \mathrm{~m} / \mathrm{sec}$. If vehicle does 
not have 4WS, sideslip angle and yaw rate increases negatively. When 4WS is applied to the system, sideslip angle and yaw rate are better but lateral displacement increases which is not preferred for safe driving. Figure 5 shows the results of 4WS which includes LKS. When LKS is included to the $4 \mathrm{WS}$ control structure, lateral displacement gets better. If the vehicle has $4 \mathrm{WS}$, sideslip angle performance (SAP), yaw rate performance (YRP) increase, lane keeping system performance (LKS) and driver workload performance (DWP) decrease. Performance results are given in Figure 6. Figure 6 shows that when LKS is included to the 4WS; SAP YRP, LKP and DWP are better than a classic vehicle.

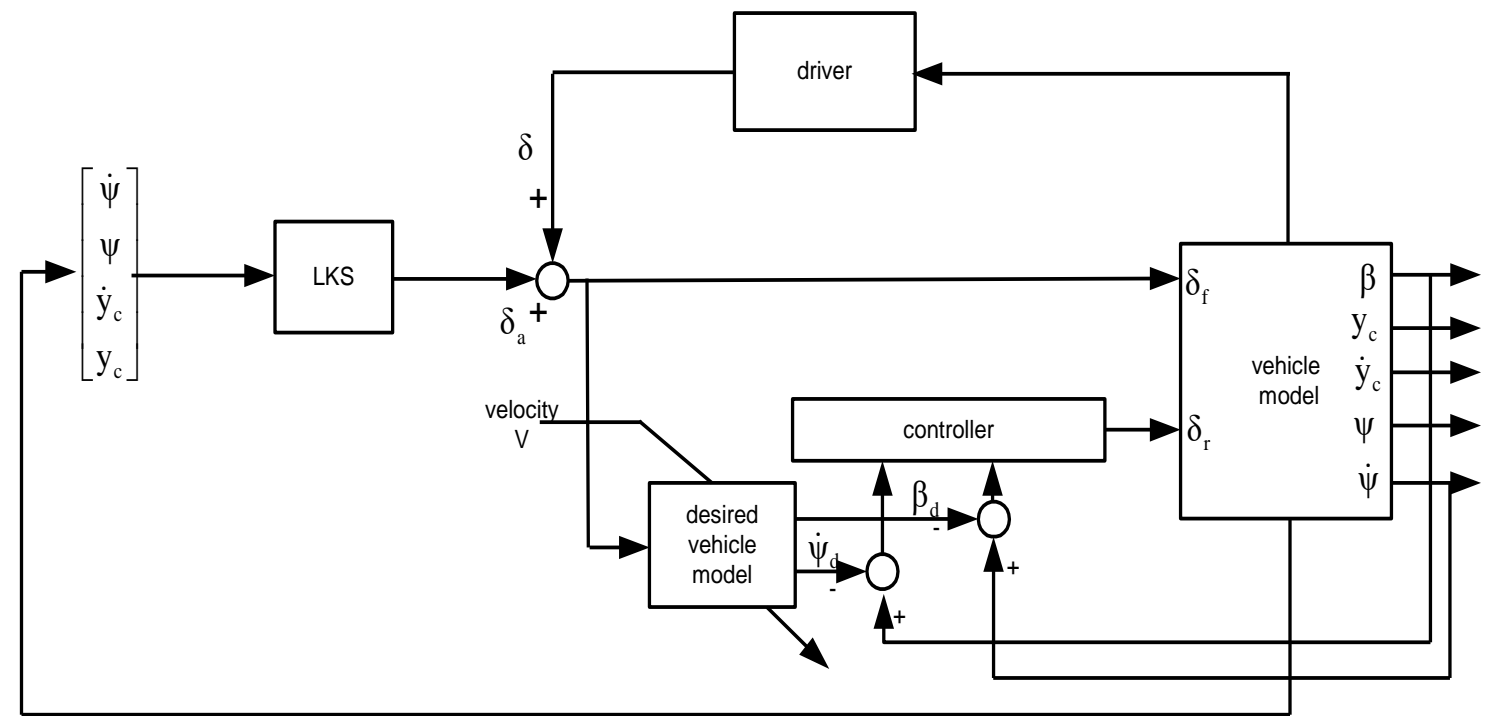

Figure 3. Structure of the designed system
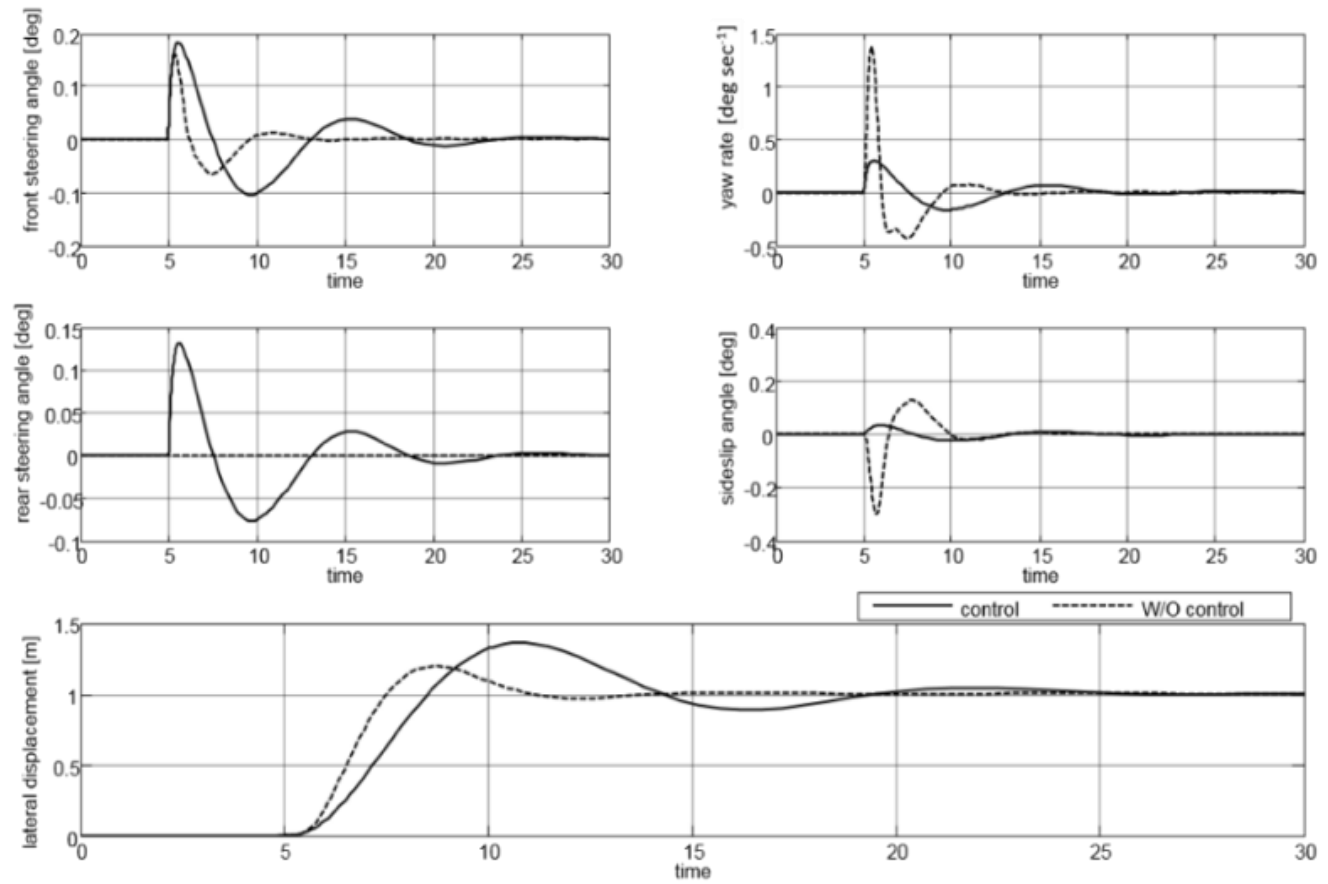

Figure 4. Results of 4WS and classic vehicle for DM-1 

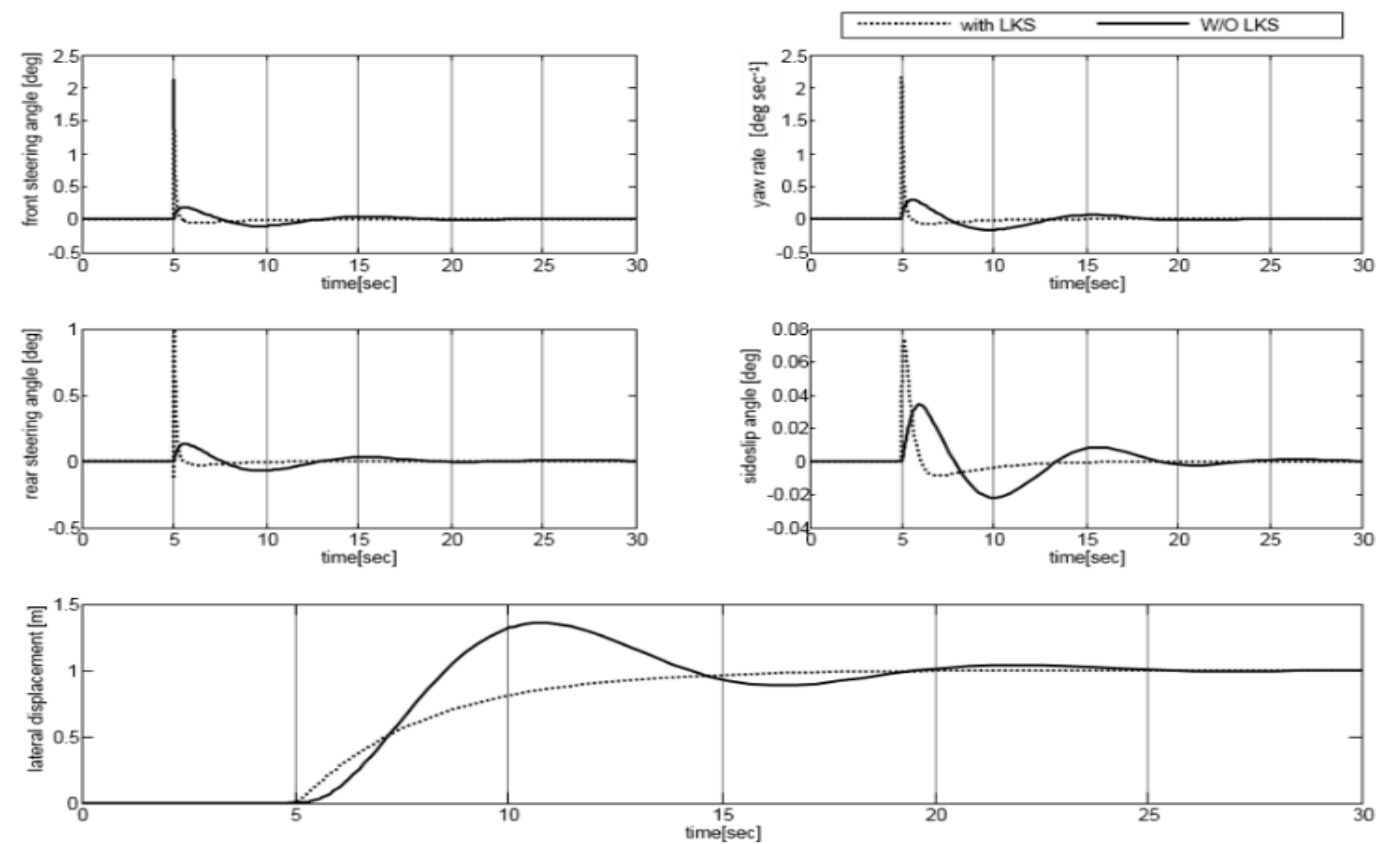

Figure 5. Results of 4WS and 4WS with LKS for DM-1
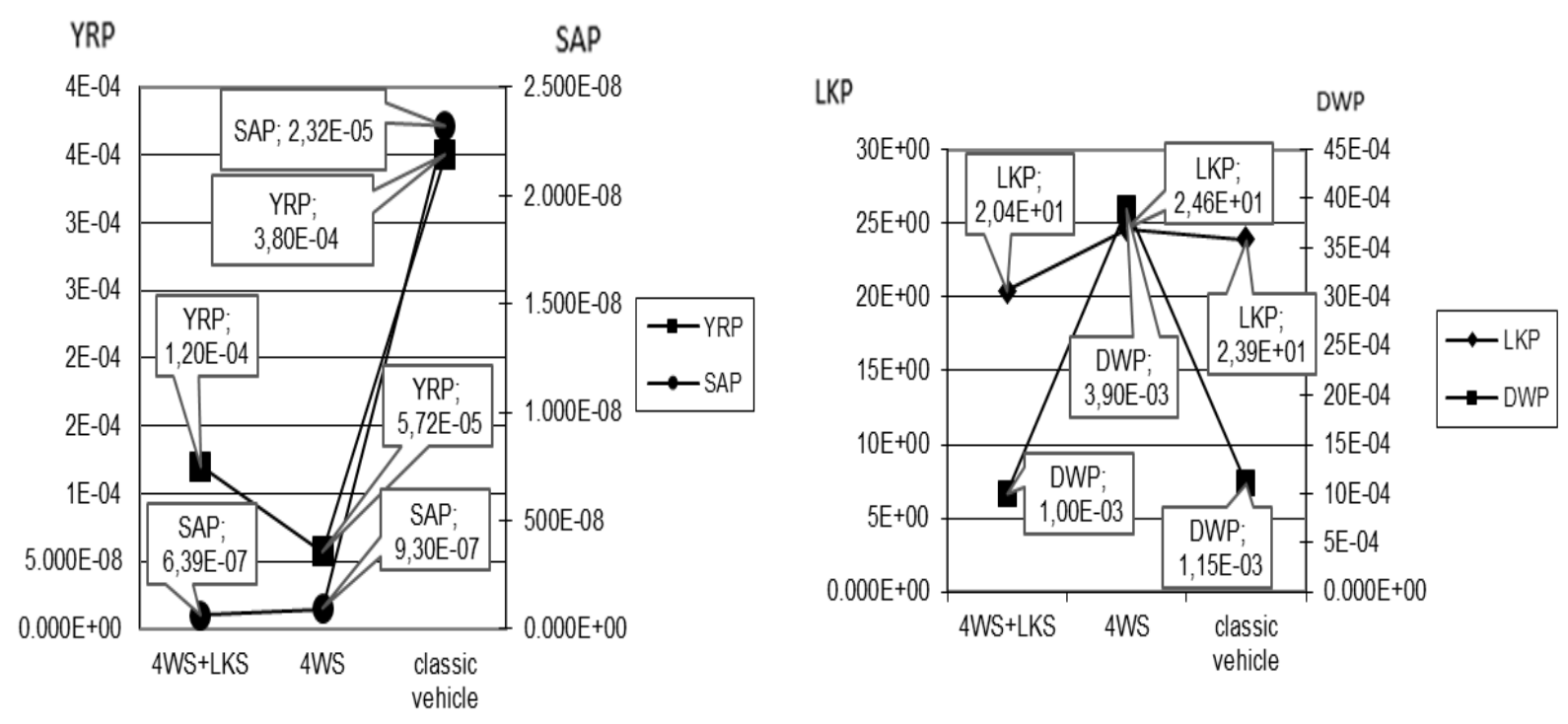

Figure 6 . Performance results for case-1

Case 2: 4WS is examined for DM-2. Vehicle speed is $50 \mathrm{~m} / \mathrm{s}$. Figure 7 shows the results of Case 2. When the vehicle does not have any controller as shown with line in Figure 7, yaw rate and sideslip angle are affected negatively. The results are given in Figure 8 for the 4WS control structure which is supported by LKS. Line shows the result of the vehicle which has only 4WS control structure, dotted line shows the effects of the 4WS which is supported by LKS.
When 4WS control structure is supported by LKS performance results are better than the vehicle which only has 4WS. When 4WS control structure compares with the classic vehicle, SAP and YRP are better on the other hand LKP and DWP are not. When 4WS control structure supported by LKS, LKP and DWP are better than which has only 4WS. Performance results are given in Figure 9. 

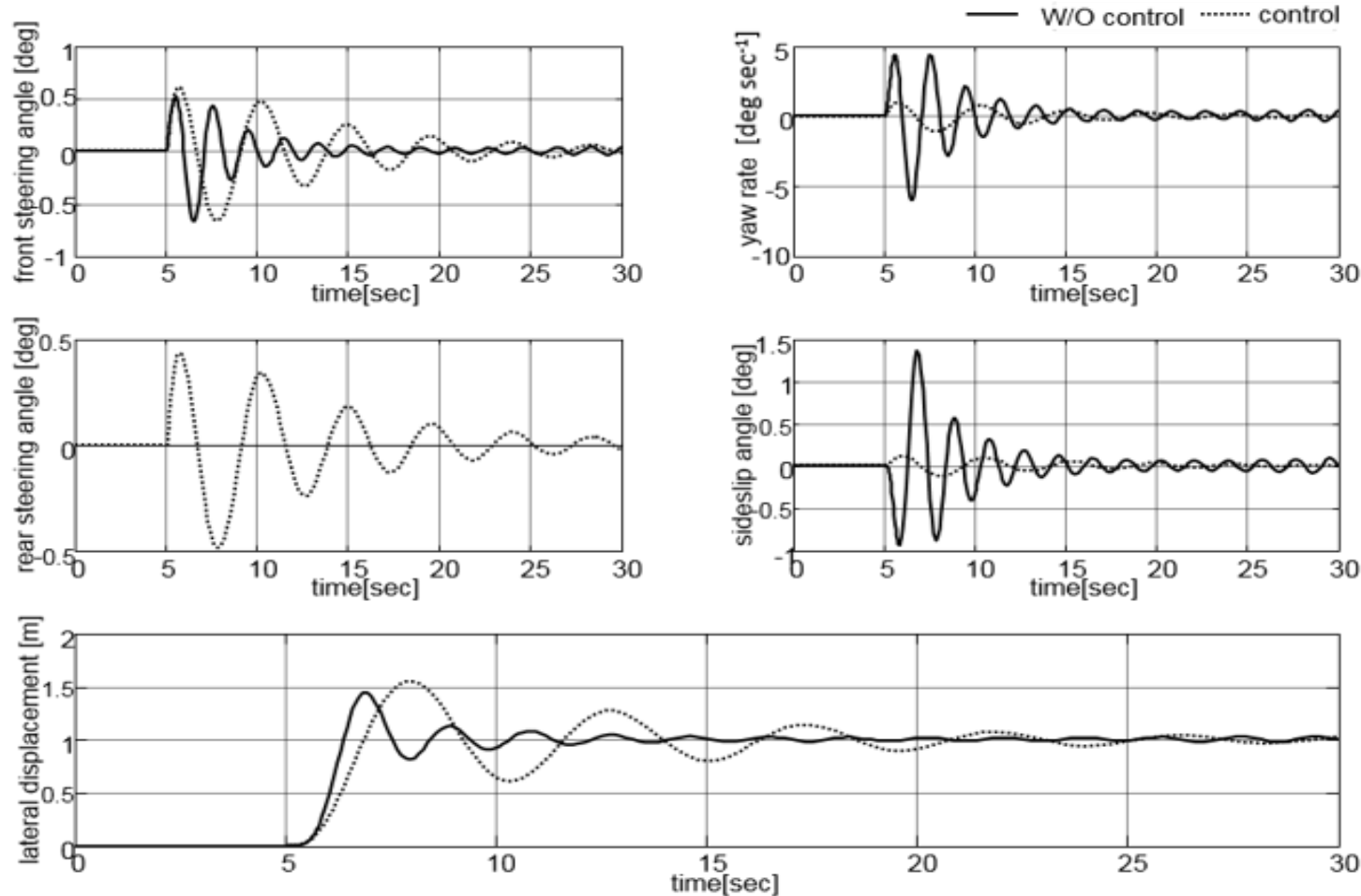

Figure 7. Results of 4WS and classic vehicle for DM-2
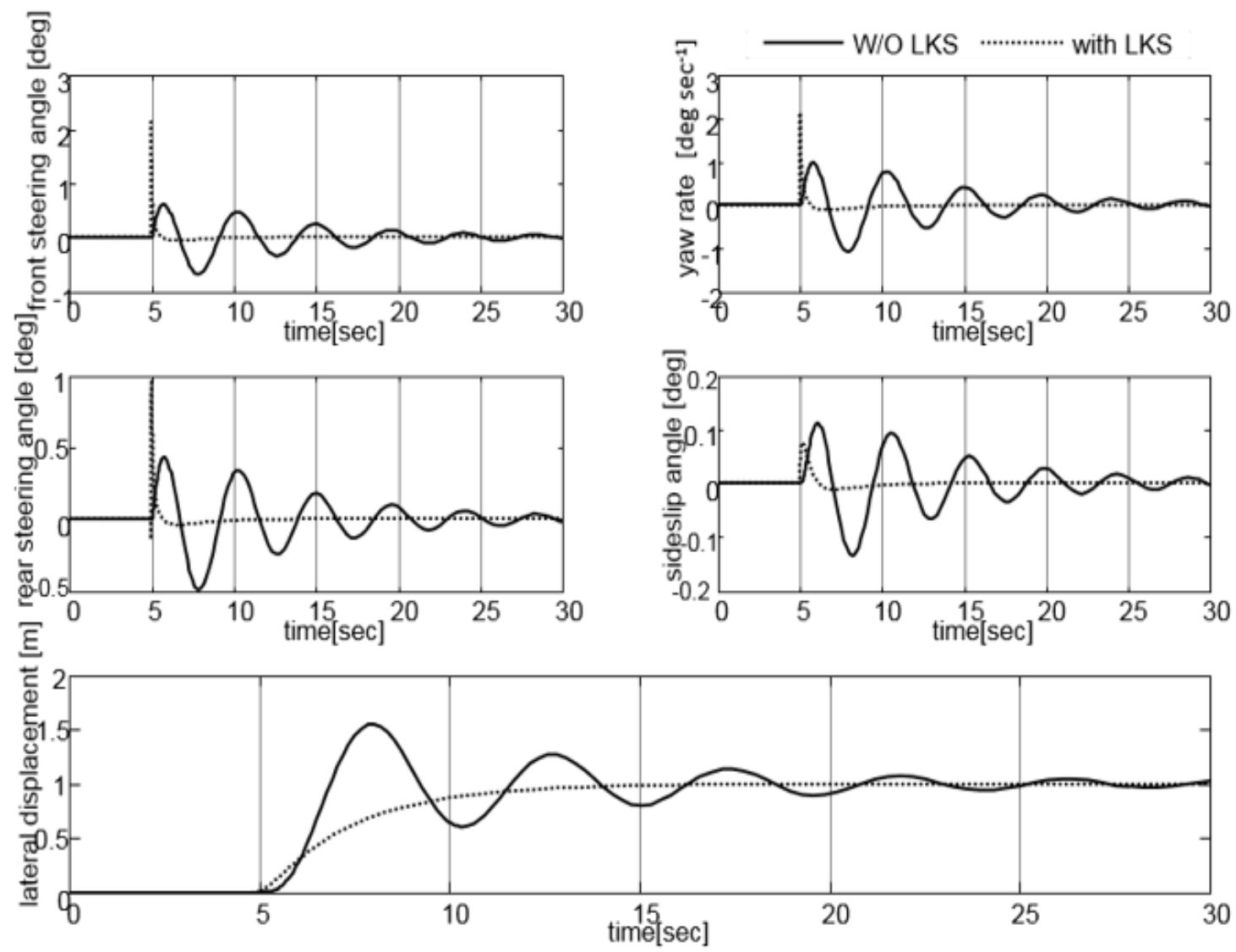

Figure 8. Results of 4WS and 4WS with LKS for DM-2 

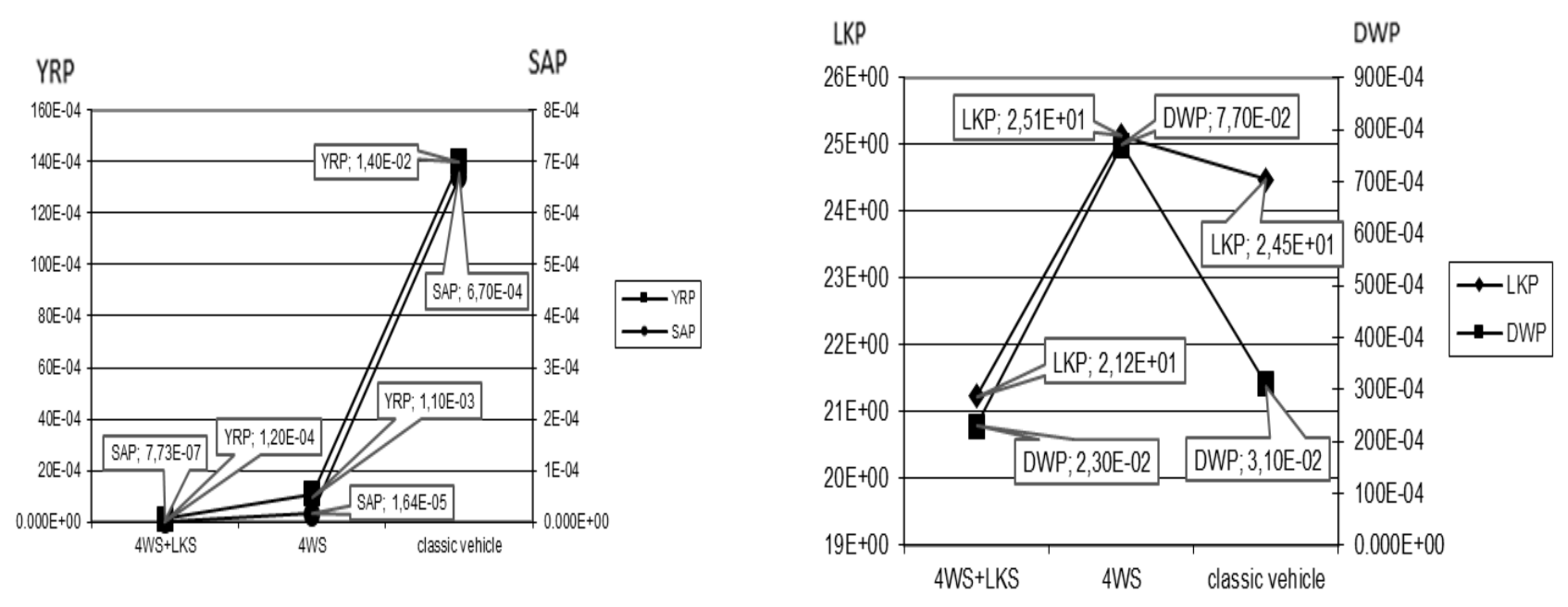

Figure 9.Performance results for case 2

Case 3: 4WS control structure effects are examined for DM-1. The vehicle speed is 35 $\mathrm{m} / \mathrm{sec}$. The result is given in Figure 10. It is clear that lateral displacement is affected badly but yaw rate and sideslip angle results are enhanced by 4WS which is shown as line in Figure 10. Dotted line shows the response of the classic vehicle for Figure 10. Figure 11 shows the response of the vehicle which has only $4 \mathrm{WS}$ control structure and 4WS control structure supported by LKS. Line
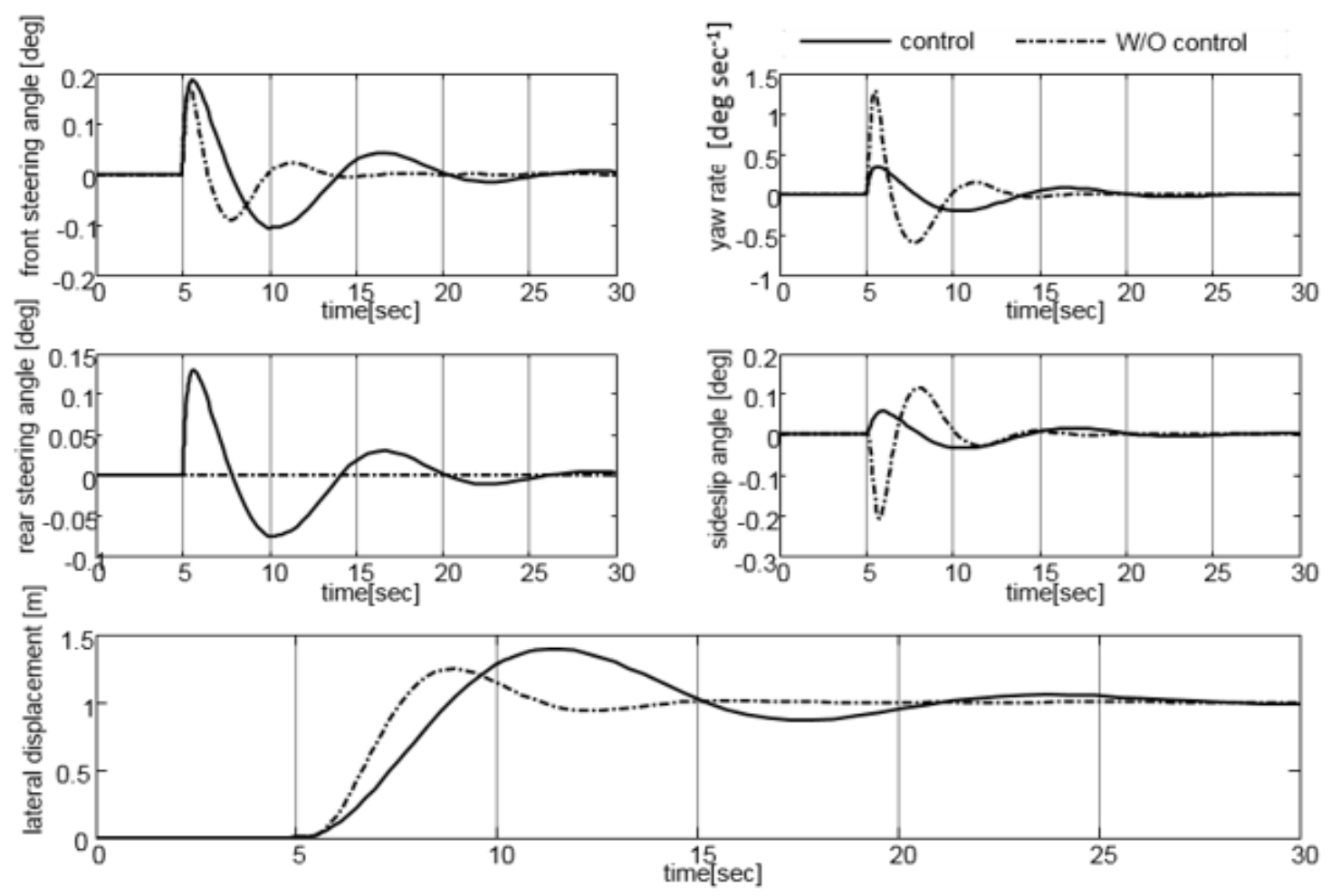

Figure 10. Results of 4WS and classic vehicle for DM-1 shows the result of the vehicle which has only 4WS control structure, dotted line shows the effects of the 4WS which is supported by LKS. When 4WS control structure supported by LKS lateral displacement and the oscillations of yaw rate and sideslip angle decrease. Figure 12 shows the performance results. 4WS with LKS performance results are better than classic vehicle performance results.
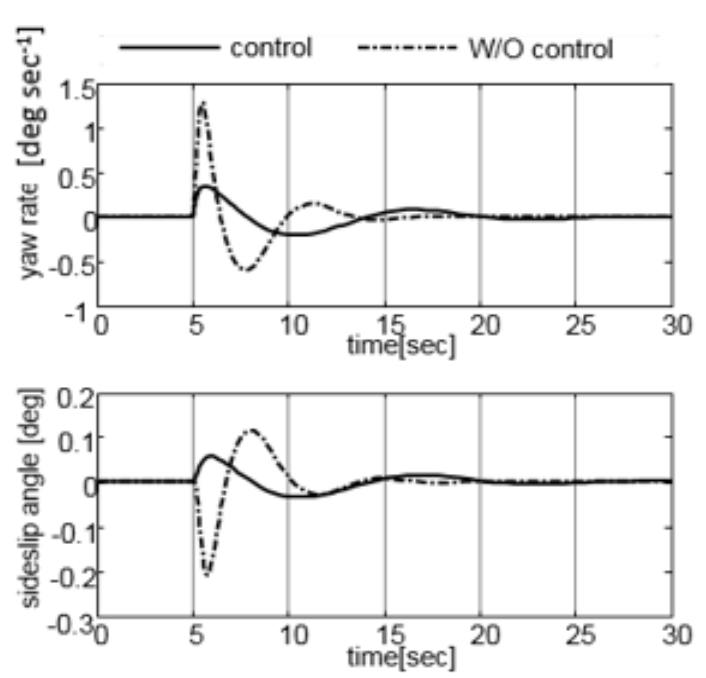

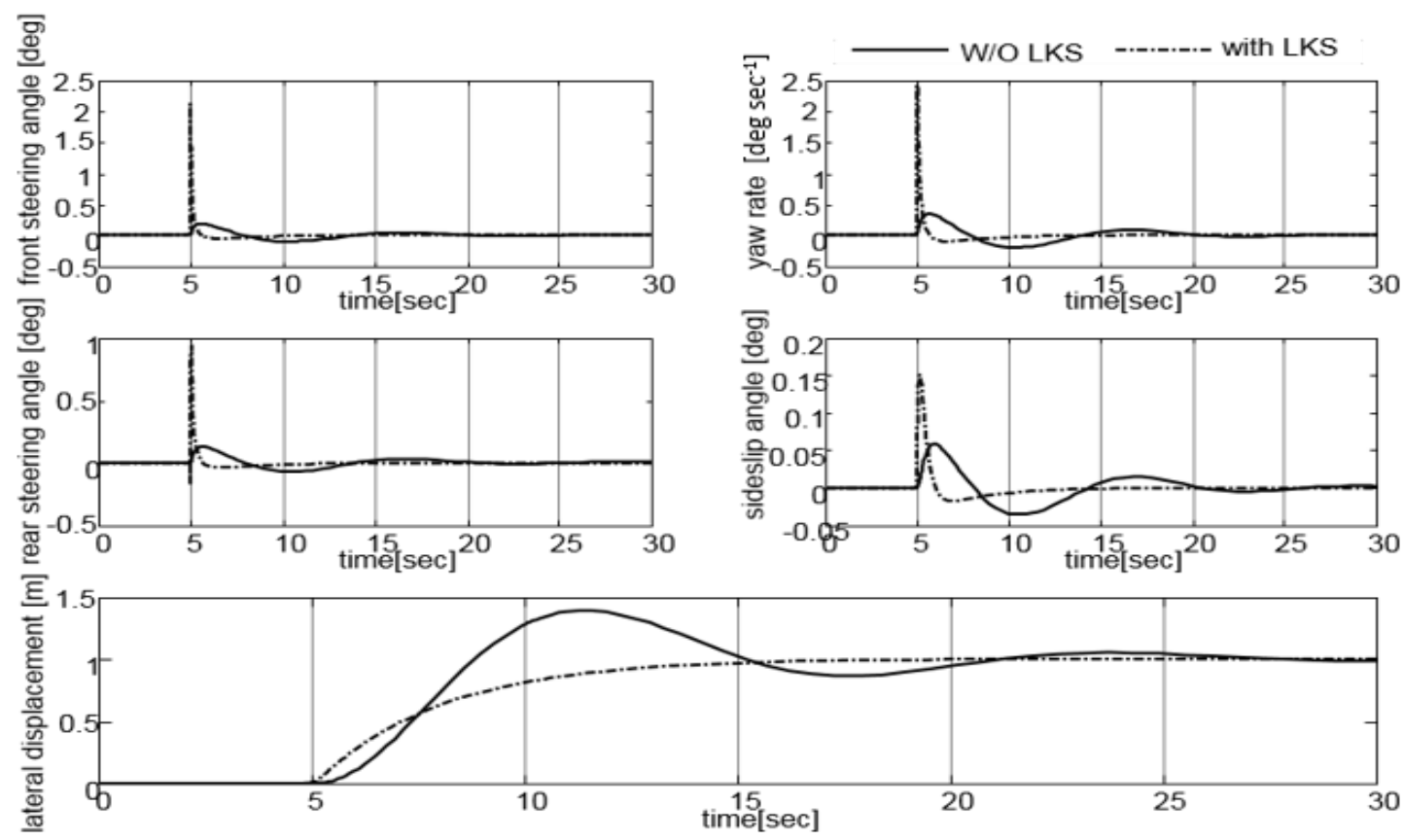

Figure 11. Results of 4WS and 4WS with LKS for DM-1
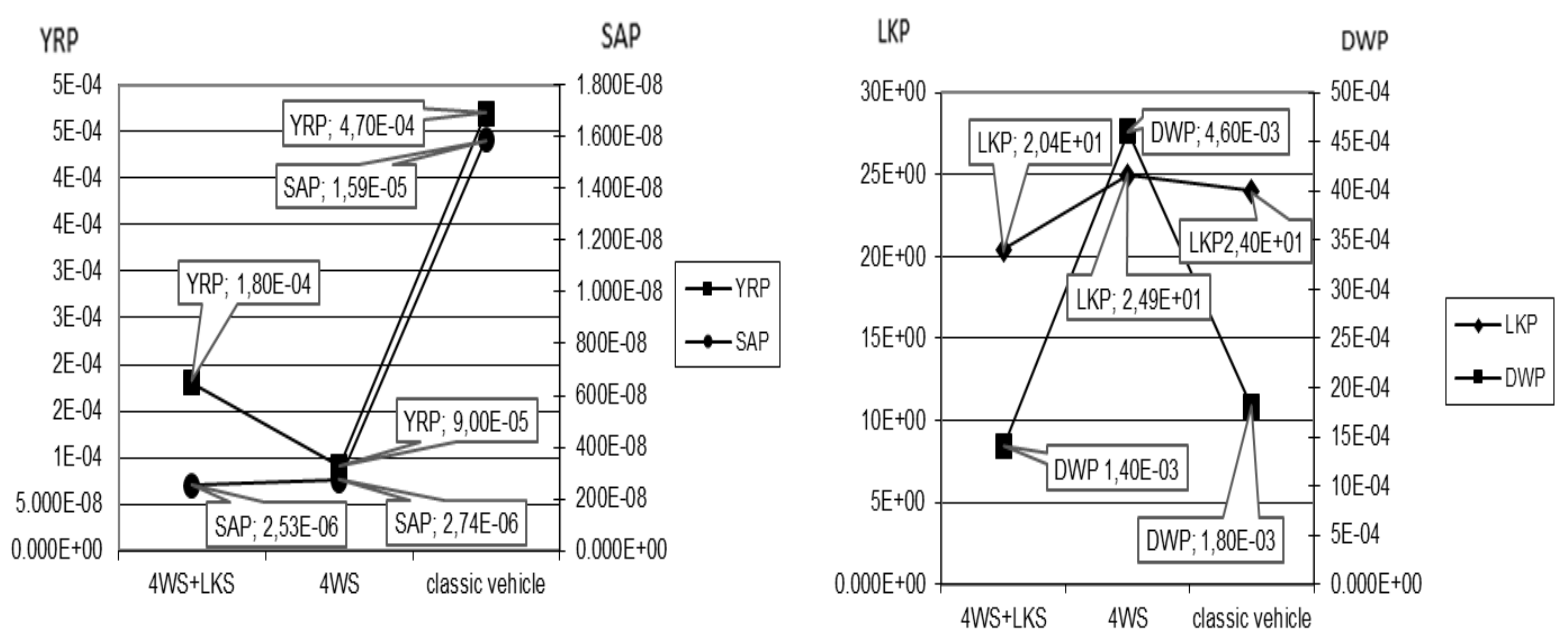

Figure 12. Performance results for case-3

Case 4:4WS response with the velocity 35 $\mathrm{m} / \mathrm{sec}$ for DM-2 is given in Figure13. Sideslip angle and yaw rate responses are not good for the classic vehicle as shown with the dotted line. It is not preferred for safety of the driver. 4WS structure enhances comfort of the driver but to get better results LKS is added to the 4WS control structure. In Figure14, line shows the results of the vehicle which has only $4 \mathrm{WS}$, dotted line shows the vehicle response with 4WS which is supported by LKS. Yaw rate and sideslip angle have an oscillation and lateral displacement increases with only 4WS control structure. When the 4WS control structure supported by LKS, oscillation disappears. Figure15 gives the performance results for the controllers. Firstly, 4WS is compared with the classic vehicle. Secondly, 4WS control structure is compared with the vehicle which has 4WS supported by LKS. It is clear from Figure 15, when 4WS control structure is supported by LKS performances are better. SAP,YRP,LKP,DWP results are seen in Figure 15. 

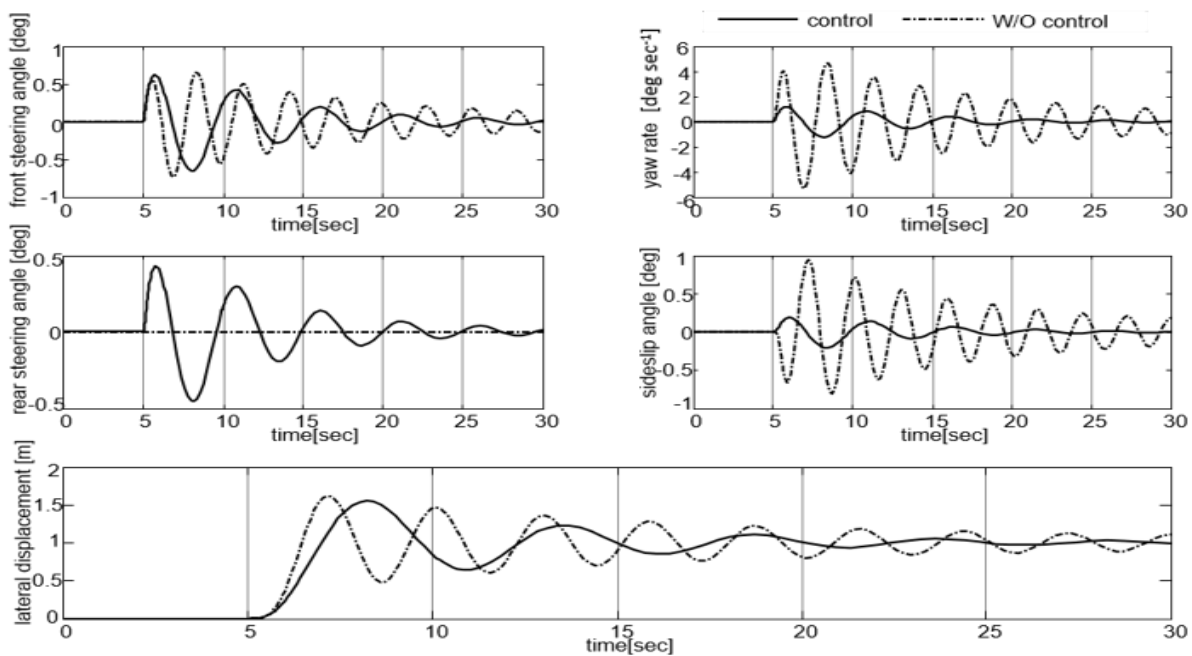

Figure 13. Results of 4WS and classic vehicle for DM-2
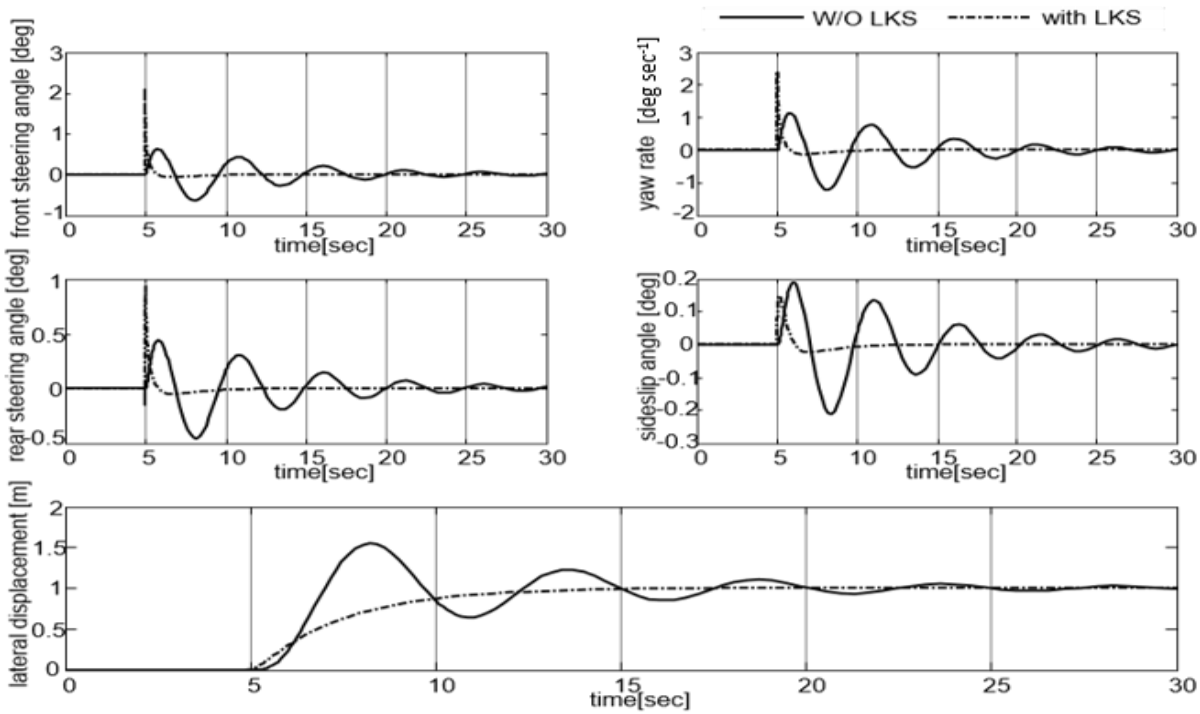

Figure 14. Results of 4WS and 4WS with LKS for DM-2
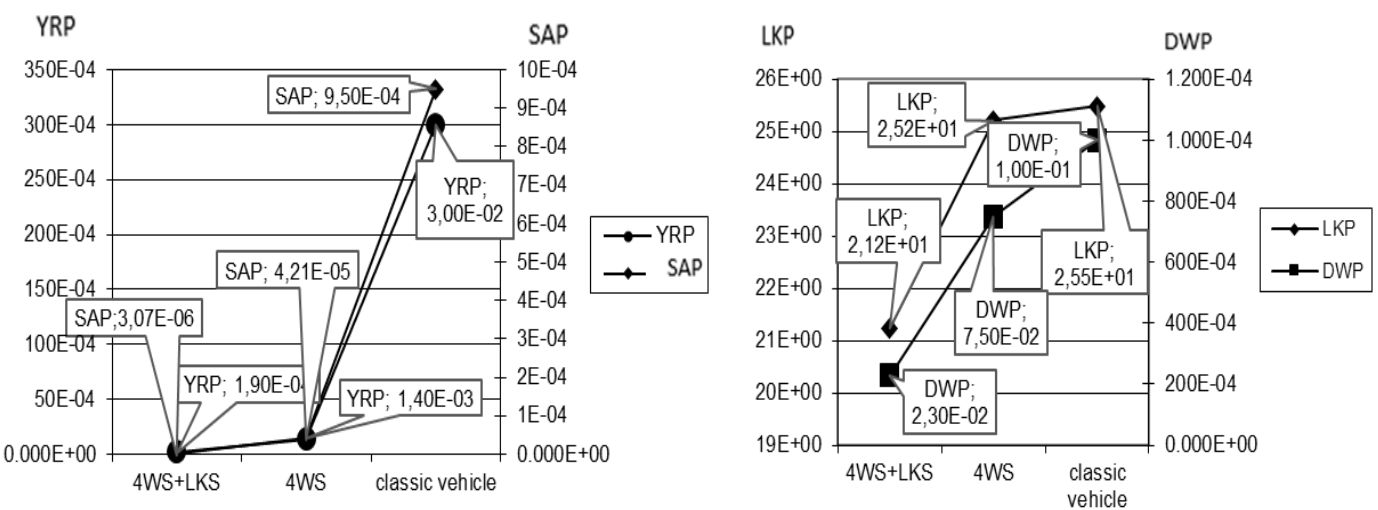

Figure 15. Performance results for case 4

\section{CONCLUSION}

In this paper, the vehicle responses are examined for the classic vehicle, the vehicle which has only 4WS and the vehicle which has
4WS with LKS. Linear vehicle model is used. Simulations are done on the vehicle model. The effectiveness of the controllers are shown with the results. The relative lateral distance and the 
relative yaw angle may not be zero using only front wheel steering. This problem is overcome using 4WS which is used front and rear wheel steering. As seen from the simulation results 4WS helps to the vehicle for yaw rate and sideslip angle performances but lateral displacement and driver workload increase. 4WS is supported by LKS to solve this problem. The major conclusion to be drawn from the study in this paper is: by integration LKS to $4 \mathrm{WS}$, the lateral and yaw dynamics, driver workload can be effectively controlled to have desirable characteristics.

\section{ACKNOWLEDGEMENT}

This research was supported by Bolu Abant Izzet Baysal University as a Scientific Research Project with a project no.2010.09.05.356.

\section{REFERENCES}

Bak T, Jakobsen H, 2004. Agricultural Robotic Platform with Four Wheel Steering for Weed Detection. Biosystems Engineering 87 (2):125-136.

Dijksterhuis C, Brookhuis K A, Waard D D, 2011. Effects of Steering Demand on Lane Keeping Behaviour, Self-Reports, and Physiology. A Simulator Study. Accident Analysis and Prevention 43:1074-1081.

Feng K T, 2000. Vehicle Lateral Control for Driver Assistance and Automated Driving. California University Graduate School of Natural and Applied Sciences, Mechanical Engineering. Phd thesis.

Fofanova J, Vollrath M, 2011. Distraction while Driving: The Case of Older Drivers. Transportation Research Part F 14: 638-648.

Huang D W, Wang H L, Zhu Z Z, Zhang F, 2007. Stochastic Stability of Four-Wheel-Steering System. Chaos solitons and fractals 33: 823-828.

Kwon S J, Fujioka T, Cho KY, Suh M W, 2005. Model Matching Control Applied to Longitudinal and Lateral Automated Driving. Proc. IMechE. Part D: J. Automobile Engineering, Vol. 219: 583-598.

Leelavansuk P, Yoshida H, Nagai M, 2003. Cooperative Steering Characteristics of Driver and Lane Keeping Assistance System. International Journal of ITS Research, Vol 1 , No 1 : 17-24.

Marino R, Scalzi S, Netto M, 2011. Nested PID Steering Control for Lane Keeping in Autonomous Vehicles. Control engineering Practice 19 : 1459-1467.
Mostavi M R, Shariatpanahi M, Kazemi R, 2004. A Novel Optimal Four Wheel Steering Control. IEEE International Conference on Industrial Technology (ICIT), 8-10 December 2004, Tunisia, pp:15961601 .

Nagai M, Shino M, Gao F, 2002, Study on integrated control of active front steer angle and direct yaw moment, JSAE Review 23 : 309-315

Özgen P S, 2012. Modeling and Simulation of Active Front Steering System. Scientific Research and Essays, 7(41) : 3479-3486.

Özgen P S, 2010. Taşıt için Sapma Denetim Sistem Tasarımı ve Benzetimi. $5^{\text {th }}$ Automotive technologies congress, June 07-08, 2010, Bursa, Turkey.

Özgen P S, 2010. Heading Control System for a Multi-body Vehicle with a Virtual Test Driver. Advances in Electrical and Computer Engineering, vol. 10, no. 3 : 11-16.

Pruckner A, Fischer S, 2000. Vehicle Dynamics Control for a 4 Wheel Steering Prototype Car. http://www.mscsoftware.com/support/library/conf/a dams/euro/2000/aachen_4wheel_steering.pdf (Date of access: 20 November 2017)

Risack R, Mohler N, Enkelmann W, 2000. A Video-based Lane Keeping Assistant. Proceedings of the IEEE Intelligent Vehicles Symposium, 5-5 October 2000, Dearborn (MI), USA, pp: 356-361.

Yang S Y, Park S T, Jeong J H, Park B R,1999. Development of Intelligent Automated Driving Control System (Lateral Control). Proceedings Third Russian-Korean International Symposium on Science and Technology. KORUS'99, 22-25 June 1999, Russia, pp: 334-337.

Yu S, Wang J, Wang Y, Chen H, (2016) Disturbance Observer Based Control for Four Wheel Steering Vehicles with Model Reference, IEEE/CAA JOURNAL OF AUTOMATICA SINICA, pp.1-7, DOI: $10.1109 /$ JAS.2016.7510220.

Zhang J, Zhang Y, Chen L, Yang J, 2007. A Fuzzy Control Strategy and Optimization for Four Wheel Steering System, IEEE International Conference on Vehicular Electronics and Safety, 13-15 Decemeber 2007, China, pp:1-6.

Zhang B, Liu C, 2011. Modeling and Simulating Research of Integrated Fuzzy Control for Automobile Steering Stability, Energy Procedia 11: 1299 - 1304. 